\title{
Argonaute protein identity and pairing geometry determine cooperativity in mammalian RNA silencing
}

\author{
JENNIFER A. BRODERICK, ${ }^{1}$ WILLIAM E. SALOMON, ${ }^{2}$ SEAN P. RYDER, ${ }^{2}$ NEIL ARONIN, ${ }^{3}$ \\ and PHILLIP D. ZAMORE ${ }^{2,4,5}$ \\ ${ }^{1}$ Program in Neuroscience, University of Massachusetts Medical School, Worcester, Massachusetts 01605, USA \\ ${ }^{2}$ Department of Biochemistry and Molecular Pharmacology, University of Massachusetts Medical School, Worcester, Massachusetts 01605, USA \\ ${ }^{3}$ Department of Medicine, University of Massachusetts Medical School, Worcester, Massachusetts 01605, USA \\ ${ }^{4}$ Howard Hughes Medical Institute, University of Massachusetts Medical School, Worcester, Massachusetts 01605, USA
}

\begin{abstract}
Small RNAs loaded into Argonaute proteins direct silencing of complementary target mRNAs. It has been proposed that multiple, imperfectly complementary small interfering RNAs or microRNAs, when bound to the 3' untranslated region of a target mRNA, function cooperatively to silence target expression. We report that, in cultured human HeLa cells and mouse embryonic fibroblasts, Argonaute1 (Ago1), Ago3, and Ago4 act cooperatively to silence both perfectly and partially complementary target RNAs bearing multiple small RNA-binding sites. Our data suggest that for Ago1, Ago3, and Ago4, multiple, adjacent small RNA-binding sites facilitate cooperative interactions that stabilize Argonaute binding. In contrast, small RNAs bound to Ago2 and pairing perfectly to an mRNA target act independently to silence expression. Noncooperative silencing by Ago2 does not require the endoribonuclease activity of the protein: A mutant Ago2 that cannot cleave its mRNA target also silences noncooperatively. We propose that Ago2 binds its targets by a mechanism fundamentally distinct from that used by the three other mammalian Argonaute proteins.
\end{abstract}

Keywords: Argonaute; cooperativity; microRNA; miRNA; RNAi; siRNA; RNA silencing

\section{INTRODUCTION}

In plants and animals, small silencing RNAs such as small interfering RNAs (siRNAs) and microRNAs (miRNAs) provide the specificity determinants for Argonaute proteins. A small RNA guide bound to an Argonaute protein is called the RNA-induced silencing complex (RISC) (Hammond et al. 2000; Hannon 2002; Du and Zamore 2007; Matranga and Zamore 2007; Ghildiyal and Zamore 2009); binding of RISC to the $3^{\prime}$ untranslated region (UTR) of an mRNA silences its expression (Lee et al. 1993; Wightman et al. 1993; Olsen and Ambros 1999; Lai 2002; Doench et al. 2003; Grimson et al. 2007). Argonaute proteins are structural homologs of RNase $\mathrm{H}$ that typically cleave their target RNAs after the nucleotide paired to the tenth base of the small RNA guide (Elbashir et al. 2001a,b; Tolia and Joshua-Tor 2007). Cleavage requires three key amino acids-D, D, $\mathrm{H}$-that form a magnesium-binding catalytic triad, which

\footnotetext{
${ }^{5}$ Corresponding author.

E-mail phillip.zamore@umassmed.edu.

Article published online ahead of print. Article and publication date are at http://www.rnajournal.org/cgi/doi/10.1261/rna.2778911.
}

promotes nucleophilic attack by hydroxide on the phosphodiester bond (Kanaya et al. 1996; Haruki et al. 2000; Martinez and Tuschl 2004; Schwarz et al. 2004; Song et al. 2004; Rivas et al. 2005).

The human genome encodes four Argonaute paralogsAgo1, Ago2, Ago3, and Ago4-and most cultured mammalian cell lines express all four proteins, albeit in different proportions (Meister et al. 2004). Of the four mammalian Argonautes, only Ago2 retains the ability to catalyze sitespecific, small RNA-directed endonucleolytic target cleavage (Liu et al. 2004; Meister et al. 2004). Like Ago2, Ago3 contains an apparent catalytic triad, but unlike Ago2, it lacks endoribonuclease activity. For Agol and Ago4, there is no catalytic triad, explaining their lack of endoribonuclease activity (Meister et al. 2004; Rivas et al. 2005; Azuma-Mukai et al. 2008). Extensive, but not complete, complementarity between a small RNA guide and an mRNA is required for Argonaute-catalyzed target cleavage (Hutvágner and Zamore 2002; Schwarz et al. 2002; Haley and Zamore 2004; Liu et al. 2004; Meister et al. 2004; Rivas et al. 2005). In contrast, small RNAs with only partial complementarity to their target mRNAs, especially those bearing mismatches near the cleavage site, cannot direct endonucleolytic cleavage of their 
target (Holen et al. 2002) but instead reduce the stability of the target mRNA (Guo et al. 2010) and, in some conditions, cause translational repression (Doench et al. 2003; Doench and Sharp 2004).

Experimental and computational analyses suggest that a single miRNA can regulate hundreds of genes, because a target mRNA need only pair with the seed sequence of a small RNA-comprising nucleotides 2 through 7 or 8 - to recruit RISC and promote repression (Lewis et al. 2003; Doench and Sharp 2004; Rajewsky and Socci 2004; Brennecke et al. 2005; Krek et al. 2005; Lewis et al. 2005; Lim et al. 2005; Grimson et al. 2007; Baek et al. 2008; Selbach et al. 2008; Friedman et al. 2009). Multiple, partially complementary small RNAs, when bound to the 3' UTR of a luciferase reporter target mRNA, may function cooperatively to repress its translation (Doench et al. 2003; Bartel and Chen 2004), and most mRNAs contain multiple potential miRNA-binding sites in their 3' UTRs (Lee et al. 1993; Wightman et al. 1993; Reinhart et al. 2000; Abrahante et al. 2003; Lin et al. 2003; Bartel 2004; Grimson et al. 2007; Friedman et al. 2009). However, the molecular basis for cooperativity in small RNA silencing remains unknown.

Here, we show that both the nature of siRNA:mRNA target pairing and the identity of the Argonaute protein to which the small RNA is bound determine whether multiple target sites act cooperatively to recruit RISC. Small RNAs that pair perfectly to multiple target sites silenced noncooperatively when the small RNA guide acts through Ago2, whereas silencing directed by either perfectly or imperfectly pairing small RNAs bound to Ago1, Ago3, or Ago4 acted cooperatively to silence mRNA bearing multiple small-RNAbinding sites. Cooperativity required adjacent sites. Surprisingly, noncooperative silencing by perfectly pairing small RNAs bound to Ago2 did not require target cleavage, as catalytically inactive mutant Ago2 silenced essentially as well as wild type. Finally, we find that computationally predicted modes of miRNA:target pairing required far more small RNA to achieve repression than more extensively but still incompletely paired small RNA guides. We propose that cooperative binding of RISC to multiple adjacent sites, combined with high intracellular concentrations of miRNAs, allows robust regulation of mRNA targets by Ago1, Ago3, and Ago4.

\section{RESULTS}

\section{Experimental paradigm}

At least three distinct regulatory mechanisms could explain the enhanced silencing of reporter mRNAs containing multiple miRNA-binding sites (Fig. 1). A cooperative binding model posits that the binding of a miRNA:Argonaute protein complex to one site increases the affinity of a second miRNA:Argonaute complex for an adjacent site (Fig. 1A). In this model, the binding of the first bulged siRNA would have a higher dissociation constant, $K_{D}^{A}$, than subsequent binding events, $K_{D}^{B}$ and $K_{D}^{C}$; we predict that the amount of siRNA required to silence a reporter would decrease with an increasing number of target sites as cooperativity between bound Argonautes increases. Such cooperativity in small RNA-directed silencing might arise from direct interactions between adjacent Argonaute proteins. Alternatively, a pair of Argonaute proteins might be bridged by one or more additional proteins. In a cooperative function
A

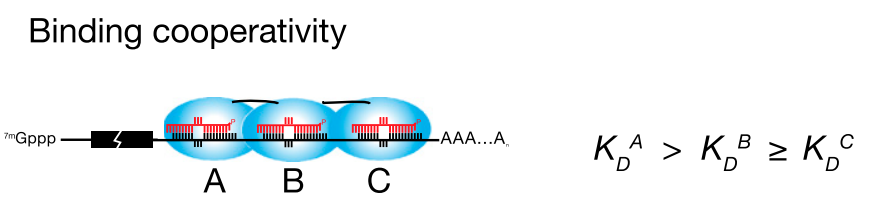

B

Functional cooperativity

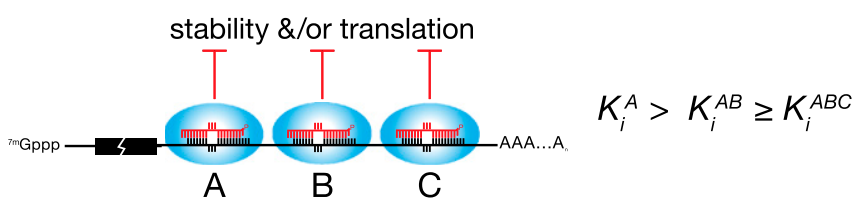

C

Multiple, independent sites
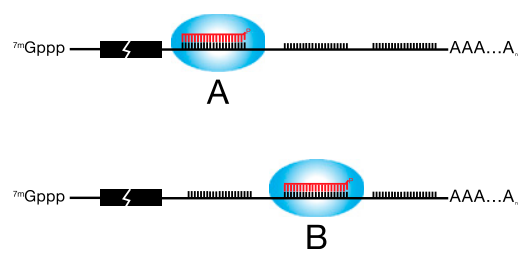

if $K_{i}^{A}=K_{i}^{B}=K_{i}^{C}$ then

for one ligand and $n$ sites,

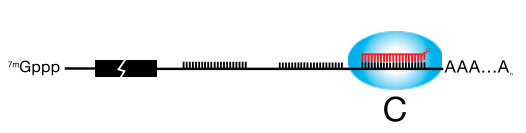

FIGURE 1. Potential sources of cooperativity in the repression of a target mRNA by the small RNA-directed Argonaute complex, RISC. ( $A$ ) Cooperative binding. RISC binding at multiple target sites increases site occupancy by mutually stabilizing subsequent binding of RISCs. $(B)$ Cooperative function. RISC binding at multiple sites may increase the likelihood that repressive factors, such as nucleases, are recruited to the mRNA. (C) Multiple independent sites. Each RISC functions independently, so the multiple sites increase the probability of repression but do not influence each other. 
model, multiple miRNA:Argonaute complexes bind to the target mRNA independently, but the interaction of one miRNA:Argonaute complex could recruit binding proteins which block translation of the target mRNA or decrease the stability of the target (Fig. 1B). Historically, such protein targets of RISC have been envisioned to include components or regulators of the ribosome but more likely correspond to factors that promote accumulation of the target RNA in a P-body, where it would be degraded (Liu et al. 2005; Rehwinkel et al. 2005; Eulalio et al. 2007; Parker and Sheth 2007; Guo et al. 2010). In the cooperative function model, we predict that the presence of three bulged siRNAs on the target would have a lower inhibitory constant, $K_{i}^{A B C}$, than for the presence of two $\left(K_{i}^{A B}\right)$ or one $\left(K_{i}^{A}\right)$ bulged siRNA; the amount of siRNA required to silence a reporter would decrease with increasing number of target sites occupied by Argonautes and/or a protein factor X, until the concentration of Argonaute or factor $\mathrm{X}$ becomes limiting. Finally, in a multiple independent sites model, each miRNA:Argonaute complex binds and acts independently, but the presence of multiple miRNA-binding sites in the target increases its effective miRNA occupancy: I.e., the probability that the target mRNA is bound by at least one miRNA is increased by the presence of multiple sites (Fig. 1C). Such statistical effects cause the macroscopic binding constant, $K$, representative of all possible combinations of target mRNA with $n$ sites where at least one site is occupied, to be determined by the statistical factors of identical microscopic binding constants, $k$, to give a fractional saturation of target: $[1 / n] k$ (Cantor and Schimmel 1980). If we assume that the $\mathrm{IC}_{50}$ is governed by binding and that the microscopic binding constant for a single site is essentially identical to the macroscopic binding constant for the one-site target, then we expect the $\mathrm{IC}_{50}$ for the three-site target to be $1 / 3\left(\mathrm{IC}_{50}\right.$, one-site target).

In contrast to the cooperativity ascribed to miRNAdirected changes in mRNA stability or translation, small RNA-guided target cleavage - that is, RNAi-is thought to be noncooperative, with each RISC acting independently at each complementary site on the target mRNA. The presence of multiple, independent small RNA-binding sites in a target would increase its effective occupancy by RISC: the probability that the target mRNA is cleaved by at least one molecule of RISC is increased by the presence of multiple sites.

To evaluate the efficacy of silencing and the extent of cooperativity directed by a small silencing RNA bound at one or multiple sites on an mRNA, we established an experimental system comprising six Renilla luciferase reporter plasmids, each expressing an mRNA bearing one to six identical, adjacent target sites in its $3^{\prime}$ UTR (Fig. 2, left). We tested four siRNAs whose guide strands pair to different extents with the target sites (Fig. 2, top). The four siRNAs enabled evaluation of four siRNA:mRNA target RNA binding modes-perfect pairing, bulged pairing (mismatched at positions 9 and 10 of the guide strand), seed pairing with supplemental $3^{\prime}$ pairing (matching the target at positions $2-8$ and $13-16$ of the guide strand), and seed-only pairing (paired only at positions 2-8 of the guide strand). Each siRNA duplex was designed to ensure preferential loading of its guide strand into RISC (Schwarz et al. 2003). Because all of our experiments comparing distinct modes of miRNA:target pairing employed a common target reporter mRNA, our strategy avoids differences in local target mRNA structure that might confound interpretation.

For each of the 24 reporter-siRNA combinations tested in HeLa cells, we calculated the concentration of siRNA required to achieve half-maximal silencing $\left(\mathrm{IC}_{50}\right)$ and the Hill coefficient $\left(n^{H}\right)$, a measure of cooperativity, using doseresponse data from at least 12 independent experiments, each evaluating silencing at $\geq 10$ siRNA concentrations and spanning a 2000 -fold concentration range. For each siRNA, we confirmed that the siRNA was inherently active by validating its ability to silence a Renilla luciferase reporter containing a single, fully complementary siRNA-binding site (Fig. 3). For the four siRNAs, the mean $\mathrm{IC}_{50}$ values \pm standard deviation for the corresponding perfect, single-site reporter mRNA ranged from $0.27 \pm 0.22 \mathrm{nM}$ to $1.33 \pm 0.78$ $\mathrm{nM}$, establishing that all four siRNAs were active.

\section{Silencing by perfect pairing at multiple sites is not cooperative}

Next, we targeted each reporter for silencing by a perfect siRNA to determine if increasing the number of target sites reduced the amount of siRNA needed to silence the reporter. Based on the multiple independent sites model, we anticipated that a reporter mRNA bearing more target sites would be more likely to recruit RISC and would, therefore, show a reduced $\mathrm{IC}_{50}$ for a fully complementary ("perfect") siRNA. Instead, our data suggest that RISC neither binds nor functions appreciably better when the target contained multiple sites (Fig. 2). In fact, reporter mRNAs bearing three $\left(\mathrm{IC}_{50}=0.75 \pm 0.93 \mathrm{nM}\right)$, four $\left(\mathrm{IC}_{50}=0.25 \pm 0.09\right.$ $\mathrm{nM})$, five $\left(\mathrm{IC}_{50}=0.41 \pm 0.33 \mathrm{nM}\right)$, or six $\left(\mathrm{IC}_{50}=0.30 \pm\right.$ $0.14 \mathrm{nM}$ ) perfect sites had essentially indistinguishable $\mathrm{IC}_{50}$ values and were silenced only slightly better than a reporter bearing a single perfect site $\left(\mathrm{IC}_{50}=0.63 \pm 0.25 \mathrm{nM}\right)$. None of the six reporters displayed positive cooperativity with the perfectly matched siRNA, with the Hill coefficients ranging from $n^{H}=0.8 \pm 0.2$ (six-site reporter) to $1.2 \pm 0.2$ (four-site reporter). None of the Hill coefficients were significantly different from $n^{H}=1(P$-value $>0.05)$ (Supplemental Fig. S1). Moreover, when the same perfect siRNA was used to silence a reporter bearing three sites separated by $19 \mathrm{nt}$, the $\mathrm{IC}_{50}$ and the Hill coefficient were similar to the mRNA reporter with a single site $\left(\mathrm{IC}_{50}=0.37 \pm 0.39\right.$ $\mathrm{nM} ; n^{H}=1.0 \pm 0.2$ ) (Fig. 4).

In general, silencing by the perfect siRNA was well described by a sigmoidal curve with a Hill coefficient of 


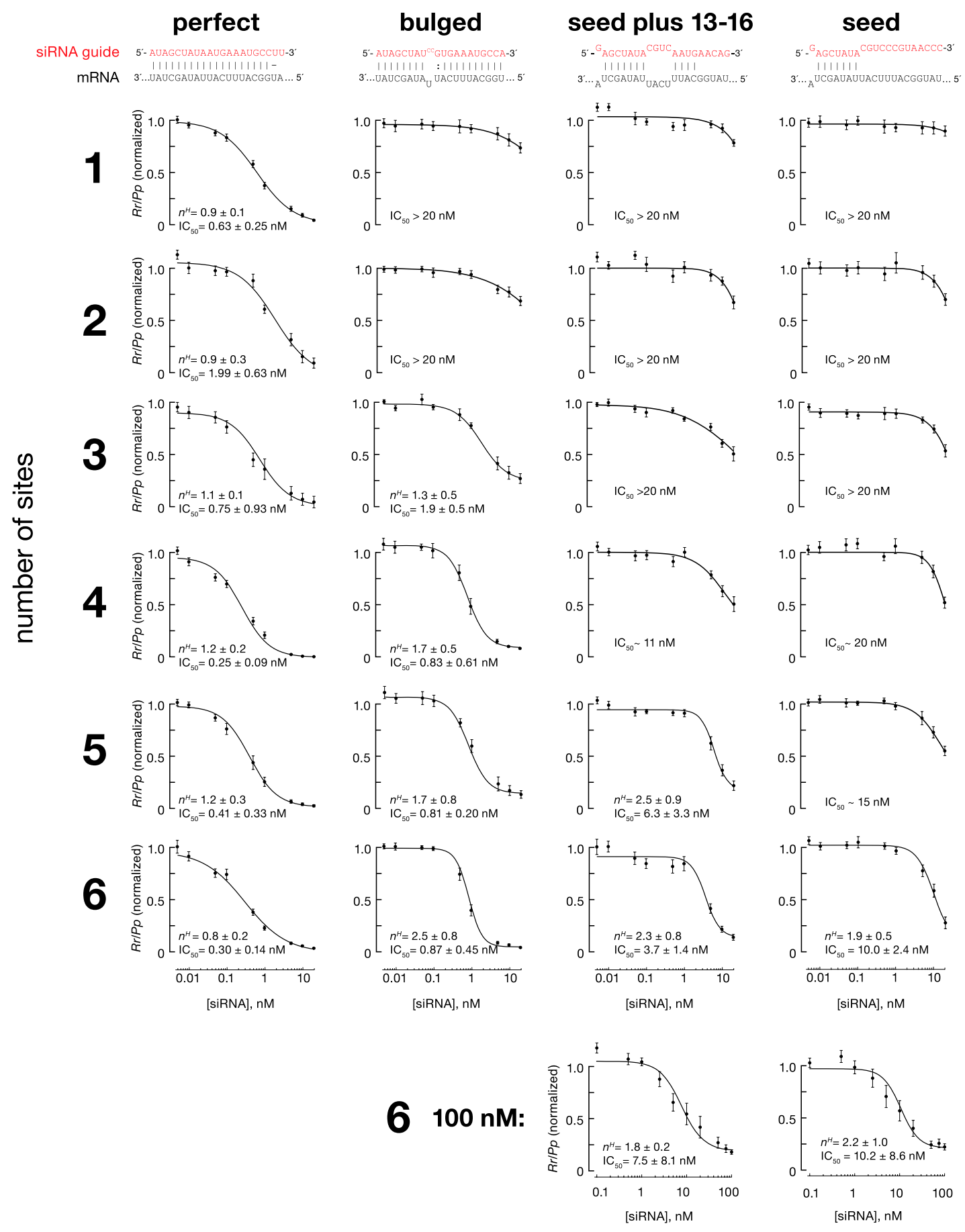

FIGURE 2. Extent of pairing and target site number determine both efficacy and cooperativity in small RNA-directed silencing in HeLa cells. Silencing of a Renilla luciferase reporter mRNA bearing 1-6 target sites in its $3^{\prime}$ UTR, relative to a firefly luciferase internal control, was determined at different siRNA concentrations. Pairing between the siRNA guide (red) to the $3^{\prime}$ UTR sites (black) is shown at top. IC $5_{50}$ and Hill coefficient $\left(n^{H}\right)$ were calculated for each dose-response curve. Throughout this study, values are reported as mean \pm standard deviation for IC so $_{50}$ values and $n^{H}$; error bars indicate standard error for $\geq 12$ biological replicates. The curves correspond to the concentration-dependence of silencing expected for the mean $\mathrm{IC}_{50}$ and $n^{H}$ values.

one, irrespective of the number of sites (Fig. 2, left). We conclude that, when guided by a perfectly pairing siRNA, each RISC acts independently from other RISCs that bind to nearby target sites.

\section{Multiple bulged sites act cooperatively}

Central internal loops—or "bulges"- -typically block siRNAor miRNA-directed target cleavage, the most potent post- 
A

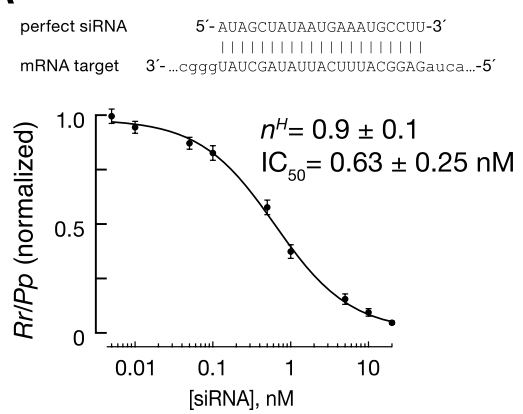

C

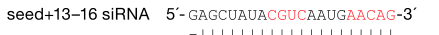
mRNA target $3-$-...cgggaucGaUAUGCAgUUACUUGUCagau....-5

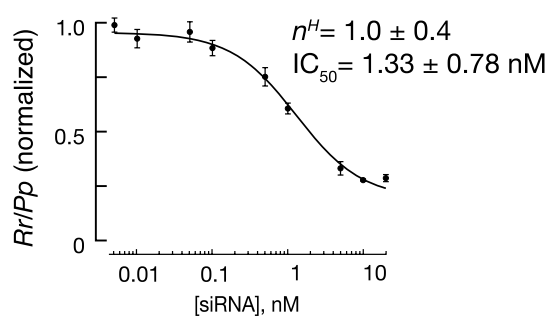

B
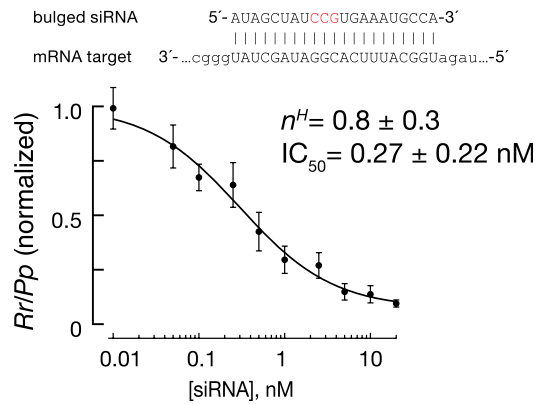

D
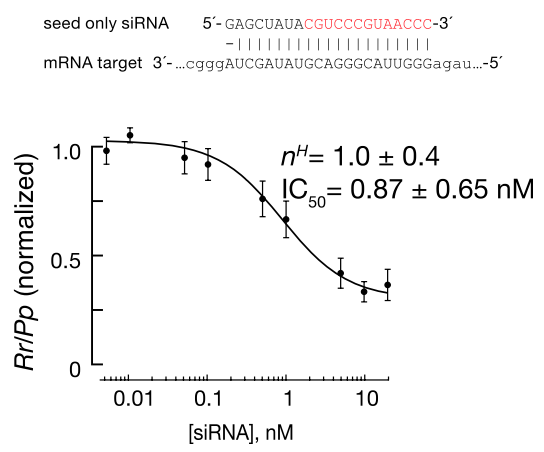

FIGURE 3. siRNA validation in HeLa cells. Each siRNA was functional in silencing a reporter containing a single perfect target site. (A) Perfect siRNA. (B) Bulged siRNA. (C) siRNA with seed plus supplementary $3^{\prime}$ pairing (nt 13-16). (D) siRNA with only seed pairing. The curves correspond to the concentration-dependence of silencing expected for the mean $\mathrm{IC}_{50}$ and $n^{H}$ values ( \pm standard deviation) calculated from three independent trials.

transcriptional silencing mechanism (Holen et al. 2002; Du et al. 2005; Dahlgren et al. 2008; Huang et al. 2009). Consistent with that view, effective silencing by a small RNA that forms a central bulge when paired to its target site required a higher concentration of siRNA than did the corresponding perfect siRNA, even when comparing multiple bulged sites to a single perfect site (Table 1; Fig. 2). In fact, we were unable to achieve half-maximal silencing of a Renilla luciferase reporter bearing one or two bulged sites even at $20 \mathrm{nM}$ transfected siRNA. For a reporter bearing six bulged sites, the $\mathrm{IC}_{50}$ was nearly three times greater than that for perfect sites. Unlike silencing mediated by perfect sites, silencing via bulged sites showed positive cooperativity, with a Hill coefficient of $2.5 \pm 0.8$ ( $P=<0.0001$ for six sites) (Table 1$)$.

\section{Seed matches and supportive pairing}

Although bulged sites have been shown to effectively silence both reporter mRNAs and endogenous genes (Zeng et al. 2002; Doench et al. 2003; Doench and Sharp 2004), they rarely occur for natural miRNAs and their endogenous targets (Lewis et al. 2003; Vella et al. 2004; Yekta et al. 2004; Brennecke et al. 2005; Lewis et al. 2005; Grimson et al. 2007). Instead, miRNAs generally pair with the mRNAs they regulate at positions $2-8$ of the guide strand-the seed sequence (Lewis et al. 2003; Brennecke et al. 2005; Krek et al. 2005; Lewis et al. 2005). Additional base pairs between the mRNA and miRNA positions 13-16 (Grimson et al. 2007) and target adenosines flanking the seed match sequence at position $1(\mathrm{t} 1 \mathrm{~A})$ and $9(\mathrm{t} 9 \mathrm{~A})$ (Lewis et al. 2005) enhance the likelihood that a miRNA will regulate a putative mRNA target.

We tested seed-matched ( $\mathrm{t} 1 \mathrm{~A})$ sites with supplemental $3^{\prime}$ pairing and seed only (t1A) sites for their ability to regulate reporter mRNA bearing one to six siRNA-binding sites. A seed match plus supplemental $3^{\prime}$ pairing required far more siRNA to achieve silencing equivalent to the bulged sites (Fig. 2). For example, the bulged siRNA regulated the three-site reporter with an $\mathrm{IC}_{50}=1.9 \pm$ $0.5 \mathrm{nM}$, whereas half-maximal silencing for the same reporter with the siRNA pairing with both the seed and supplemental 3' nucleotides could not be achieved even using $20 \mathrm{nM}$ siRNA. With six sites in the reporter, the siRNA with seed plus supplemental 3' pairing achieved an $\mathrm{IC}_{50}=3.7 \pm 1.4 \mathrm{nM}$. The seed siRNA was even less potent, reaching half-maximal silencing at a siRNA concentration of $10 \pm 2.4 \mathrm{nM}$ only for the reporter mRNA with six sites; the $\mathrm{IC}_{50}$ could not be reliably determined for mRNAs with fewer than six sites. Our data suggest that the intracellular concentration of functional miRISC exceeds the RISC concentration we achieved using transfected, synthetic siRNA duplexes.

Most studies of small RNA-directed silencing report the extent of repression ("fold-repression") for a single concentration of small RNA. To permit comparison of our data to those in the published literature, we used our data to calculate the observed "fold-repression" of the multiple-site reporters by the seed-only siRNA (Supplemental Table S1). Like Grimson et al. (2007) before us, we observe a $\geq 1$.4-fold repression of targets bearing two or more small RNA-binding sites when using the seed-only siRNA. For three or more sites, the observed repression, which ranged from 1.8- to 4.8fold, was significantly different from that predicted by a multiple, independent sites model $(0.002 \leq P \leq 0.04)$ (Supplemental Table S1).

\section{Cooperativity requires adjacent target sites}

Silencing for bulged sites displayed positive cooperativity for all multiple-site reporter mRNAs for which we could 
A

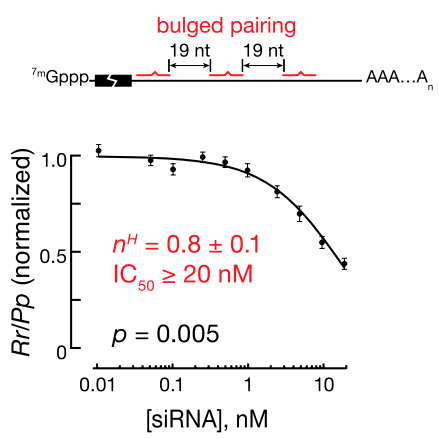

B

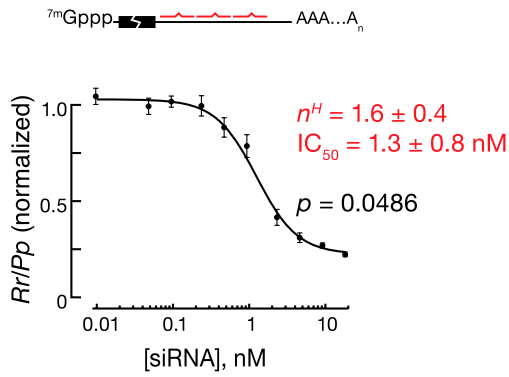

C
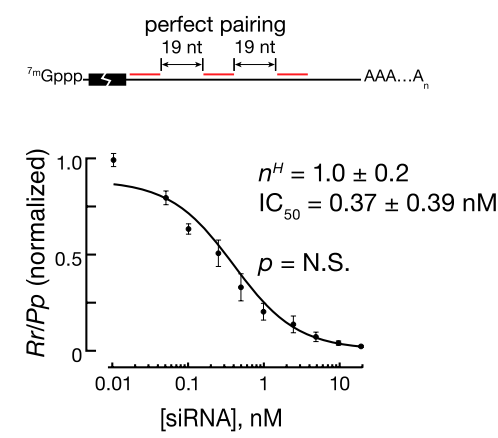

D

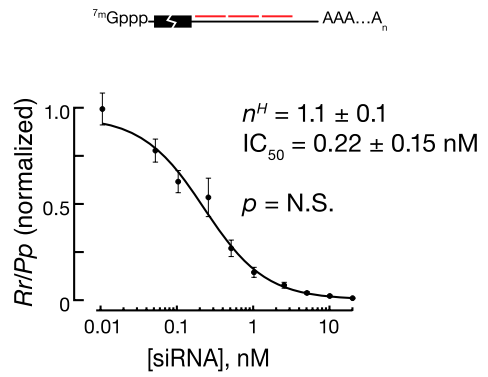

FIGURE 4. Cooperative binding of RISC requires adjacent target sites in HeLa cells. Three sites spaced $19 \mathrm{nt}$ apart $(A)$ require more siRNA to achieve half-maximal silencing, compared to three adjacent sites $(B)$, and act noncooperatively. In contrast, a perfectly matched siRNA silences a three-site reporter with sites separated by $19 \mathrm{nt}(C)$ or a reporter with three adjacent sites $(D)$ with equal efficacy and without detectable cooperativity. The three adjacent-site experiments in this figure were performed independently from those in Figure 2. A one sample, two-tailed Student's $t$-test was used to calculate the $P$-values at $95 \%$ confidence for the Hil coefficients to determine if $n^{H}$ was significantly different from the null hypothesis: $n^{H}=1$ (i.e., noncooperative).

measure the $\mathrm{IC}_{50}$ and Hill coefficient. To test if the sites need to be adjacent in order to observe positive cooperativity, we altered the sequence of every other target site in the six-site Renilla luciferase mRNA to create a three-site reporter in which $19 \mathrm{nt}$ separate each site targeted by the siRNAs (Fig. 4A). Silencing of this expanded three-site reporter mRNA by the bulged siRNA required $>15$-fold more siRNA and showed no evidence of cooperativity $\left(\mathrm{IC}_{50} \geq 20\right.$ $\left.\mathrm{nM} ; n^{H}=0.8 \pm 0.1\right)($ Fig. $4 \mathrm{~A}$ ) relative to the reporter mRNA in which the three sites were adjacent $\left(\mathrm{IC}_{50}=1.3 \pm 0.8 \mathrm{nM} ; n^{H}=1.6 \pm 0.4\right)$ (Fig. 4B).

In theory, these data might reflect reduced target-site accessibility in the expanded three-site reporter (Brown et al. 2005; Ameres et al. 2007; Tafer et al. 2008). We view this as unlikely. First, both the adjacent and expanded threesite reporters were silenced equally well by a perfectly pairing siRNA $\left(\mathrm{IC}_{50}=\right.$ $0.37 \pm 0.39 \mathrm{nM}$ versus $0.22 \pm 0.15 \mathrm{nM}$ ) (Fig. 4C,D). Second, antisense oligonucleotide-directed RNase $\mathrm{H}$ cleavage at each of the target sites occurred with similar rates $\left(6.1,6.0\right.$, and $6.6 \mathrm{nM} \mathrm{min}^{-1}$ for sites 1, 2, and 3, respectively) (Supplemental Fig. S2). Finally, the RNase $\mathrm{H}$ cleavage kinetics fit better to a model of independent action compared to a dependent, sequential model for cleavage at each site (Supplemental Fig. S2).

Silencing by the perfectly paired siRNA was noncooperative for both the expanded $\left(n^{H}=1.0 \pm 0.2\right)$ and original $\left(n^{H}=1.1 \pm 0.1\right)$ three-site reporter mRNAs (Fig. 4C,D). The observation that cooperative silencing by a small RNA requires that fewer than $19 \mathrm{nt}$ separate the RISC-binding sites to promote efficient, cooperative silencing suggests that cooperativity springs from interactions between adjacent Argonaute-siRNA complexes, rather than cooperative recruitment of proteins involved in subsequent steps in repressing mRNA expression.

\section{Ago2-RISC binding prevents cooperative silencing}

A simple explanation for why Ago2 acts noncooperatively to silence a multiple-site reporter with a perfect guide is

TABLE 1. Concentration-dependence and cooperativity for distinct siRNA:target pairing modes using reporters bearing one to six siRNA-binding sites

\begin{tabular}{|c|c|c|c|c|c|c|c|c|c|}
\hline \multirow[b]{2}{*}{ Number of sites } & \multicolumn{2}{|c|}{ Perfect } & \multicolumn{3}{|c|}{ Bulged } & \multicolumn{2}{|c|}{ Seed plus $13-16$} & \multicolumn{2}{|c|}{ Seed only } \\
\hline & $\mathrm{IC}_{50}$ & $n^{H}$ & & $\mathrm{IC}_{50}$ & $n^{H}$ & $\mathrm{IC}_{50}$ & $n^{H}$ & $\mathrm{IC}_{50}$ & $n^{H}$ \\
\hline 1 & $0.63 \pm 0.25$ & $0.9 \pm 0.1$ & & $>20$ & N.D. & $>20$ & N.D. & $>20$ & N.D. \\
\hline 2 & $1.99 \pm 0.63$ & $0.9 \pm 0.2$ & & $>20$ & N.D. & $>20$ & N.D. & $>20$ & N.D. \\
\hline 3 & $0.75 \pm 0.93$ & $1.1 \pm 0.1$ & 1.9 & \pm 0.5 & $1.3 \pm 0.5$ & $>20$ & N.D. & $>20$ & N.D. \\
\hline 4 & $0.25 \pm 0.09$ & $1.2 \pm 0.2$ & 0.83 & \pm 0.61 & $1.7 \pm 0.5$ & $\sim 11$ & N.D. & $\sim 20$ & N.D. \\
\hline 5 & $0.41 \pm 0.33$ & $1.2 \pm 0.3$ & 0.81 & \pm 0.20 & $1.7 \pm 0.8$ & $6.3 \pm 3.3$ & $2.5 \pm 0.9$ & $\sim 15$ & N.D. \\
\hline 6 & $0.30 \pm 0.14$ & $0.8 \pm 0.2$ & 0.87 & \pm 0.45 & $2.5 \pm 0.8$ & $3.7 \pm 1.4$ & $2.3 \pm 0.8$ & $10.0 \pm 2.4$ & $1.9 \pm 0.5$ \\
\hline
\end{tabular}

(N.D.) not determined. $\mathrm{IC}_{50}$ values $(\mathrm{nM})$ and Hill coefficients $\left(n^{H}\right)$ of the fitted curves are reported as mean values \pm standard deviation for the $I_{50}$ and Hill coefficients for at least 12 trials. 
that silencing reflects the endonucleolytic activity unique to mammalian Ago2. To test this idea, we evaluated silencing of the six-site reporter mRNA in three mouse embryonic fibroblast (MEF) cell lines derived from an Ago2 knockout mouse: Ago $2^{-1-}$ MEFs, Ago2 $2^{-/-}$MEFs reconstituted with mouse Ago2, and Ago $2^{-1-}$ MEFs reconstituted with a mutant mouse Ago2 in which aspartic acid 669 was changed to alanine (D669A) (O'Carroll et al. 2007). The D669A mutant Ago 2 cannot cleave an RNA target (Liu et al. 2004). In Ago $2^{-1-}$ MEF cells, the perfect siRNA and the bulged siRNA were both cooperative: $n_{\text {perfect }}^{H}=1.6 \pm 0.4 ; P=0.03$, and $n_{\text {bulged }}^{H}=1.8 \pm 0.3 ; P=0.006$ (Fig. 5A). These data suggest that Ago1, Ago3, and Ago4 bind cooperatively to a reporter mRNA bearing multiple small RNA-binding sites, irrespective of the nature of small RNA:target pairing.

As expected, repression mediated by a perfectly pairing siRNA was noncooperative $\left(n_{\text {perfect }}^{H}=1.0 \pm 0.1\right)$ in Ago $2^{-1-}$ MEFs reconstituted with overexpressed Ago2 (Figs. 5B, 6). In contrast, silencing directed by the bulged siRNA in the Ago2-reconstituted cells was cooperative $\left(n_{\text {bulged }}^{H}=1.5 \pm\right.$ $0.2 ; P=0.02$ ) (Fig. 5B). To test whether the apparent cooperativity observed in reconstituted Ago 2 MEF cells was caused by Ago2 overexpression, we measured silencing in
Ago1 $^{-1-}$ MEF cells, which express far less Ago2 mRNA and protein than reconstituted Ago $2^{-l-}$ MEF cells (Figs. 5D, 6; Supplemental Table S2). (All four Argonautes are expressed in the HeLa line we used [Supplemental Fig. S3].) We detected no cooperativity for silencing by the perfect siRNA in the Ago $1^{-/-}$MEFs $\left(n_{\text {perfect }}^{H}=1.1 \pm 0.1\right)$. However, silencing by the bulged siRNA was cooperative $\left(n_{\text {bulged }}^{H}=1.7 \pm 0.2\right.$; $P=0.003$ ), suggesting that Ago2 is capable of cooperative silencing (Fig. 5D).

To test whether Ago3 or Ago4 contributes to the cooperativity that we observed for a bulged siRNA in the Ago1 $^{-1-}$ MEFs, we used siRNAs to deplete Ago3 and Ago4 mRNAs before transfecting the reporter plasmids and bulged siRNA. Ago 4 mRNA was reduced 50\% compared to Ago ${ }^{-1-}$ MEF cells transfected with a control siRNA. By qRT-PCR, we detected Ago3 mRNA two threshold cycles after detection of Agol mRNA in the Ago1 ${ }^{-1-}$ MEF cells, indicating that its expression is probably functionally inconsequential in our analysis (data not shown). The level of Ago3 protein in Ago1 ${ }^{-/-}$MEFs was very low, and our attempts to reduce it further by RNAi were unsuccessful (Supplemental Fig. S4A). Under these conditions, $n^{H}$ for silencing by the bulged siRNA was not significantly different
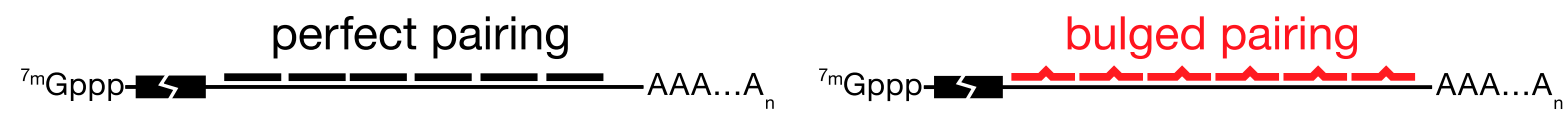

A

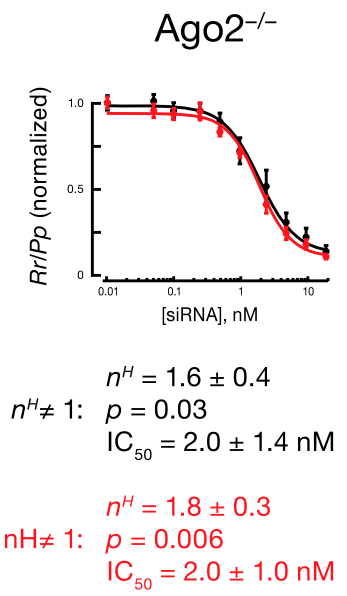

$n^{H}$ perfect vs. bulged: $p=$ N.S.
B

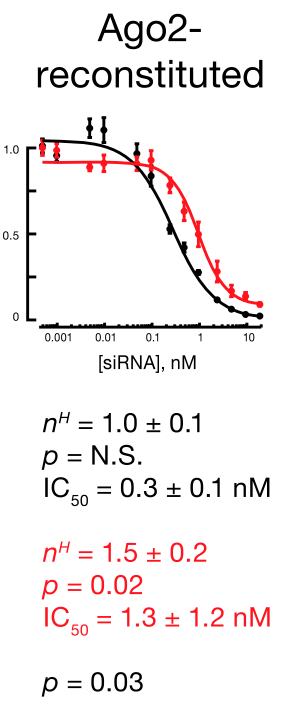

C
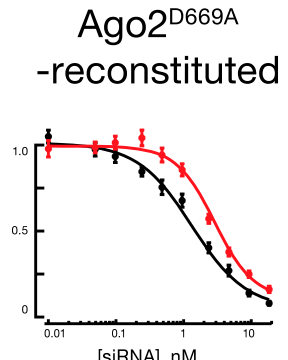

$n^{H}=1.1 \pm 0.1$

$p=$ N.S.

$\mathrm{IC}_{50}=1.4 \pm 0.5 \mathrm{nM}$

$n^{H}=1.5 \pm 0.3$

$p=0.04$

$\mathrm{IC}_{50}=3.1 \pm 1.2 \mathrm{nM}$

$p=0.007$
D

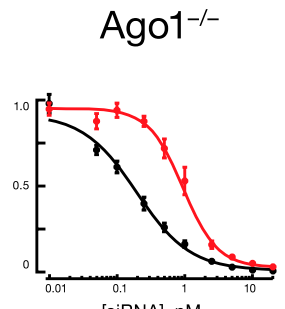

[siRNA], nM

$n^{H}=1.1 \pm 0.1$

$p=$ N.S.

$\mathrm{IC}_{50}=0.2 \pm 0.1 \mathrm{nM}$

$n^{H}=1.7 \pm 0.2$

$p=0.003$

$\mathrm{IC}_{50}=0.9 \pm 0.4 \mathrm{nM}$

$p=0.0004$

FIGURE 5. Silencing in Ago $2^{-l-}$ MEFs or Ago $2^{-/-}$MEFs reconstituted with mouse Ago2 or catalytically inactive, mutant Ago $2^{\mathrm{D} 669 \mathrm{~A}}$ or Ago1 ${ }^{-l-}$ MEFs. (A) In the absence of Ago2, silencing by a perfect site $\left(n^{H}=1.6 \pm 0.4 ; P=0.03\right)$ is equally cooperative as a bulged site $\left(n^{H}=1.8 \pm 0.3 ; P=\right.$ 0.006). (B) Mouse Ago2 expression restored noncooperative silencing by the perfect siRNA (black; $n^{H}=1.0 \pm 0.1$ ); silencing directed by a bulged siRNA became less cooperative (red; $n^{H}=1.5 \pm 0.2 ; P=0.02$ ) than in the absence of Ago2 (red in $A ; n^{H}=1.8 \pm 0.3$ ). (C) Catalytically inactive mouse Ago $2^{\mathrm{D} 669 \mathrm{~A}}$ likewise restored noncooperative silencing by a perfect siRNA (black; $n^{H}=1.1 \pm 0.1$ ), but silencing by the bulged siRNA (red; $\left.n^{H}=1.5 \pm 0.3 ; P=0.04\right)$, was cooperative. $(D)$ In the absence of Agol, silencing by the perfect siRNA was not cooperative (black; $\left.n^{H}=1.1 \pm 0.1\right)$, but silencing by the bulged siRNA was cooperative (red; $n^{H}=1.7 \pm 0.2 ; P=0.003$ ). A one sample, two-tailed Student's $t$-test was used to calculate the $P$-values at $95 \%$ confidence for the Hill coefficients to determine if $n^{H}$ was significantly different from the null hypothesis: $n^{H}=1$ (i.e., noncooperative). 


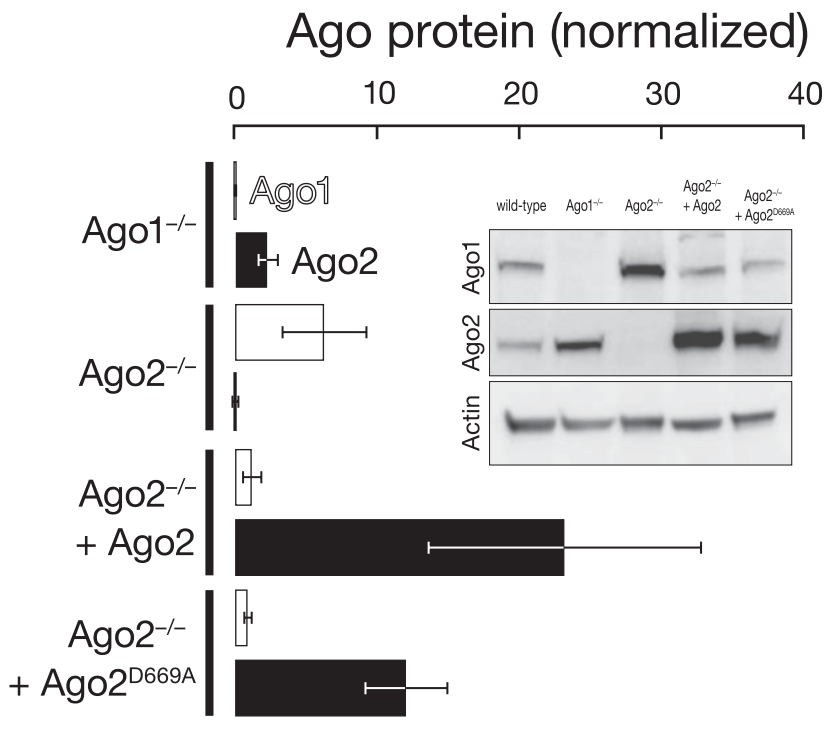

FIGURE 6. Ago1 and Ago 2 protein levels in MEF cells. Ago 2 was detected by Western blotting using a rabbit anti-Agol antibody that recognizes both mouse and human Ago1 and a rabbit anti-Ago2 antibody that recognizes both mouse and human Ago2. Ago protein levels were normalized to actin, and the level of Ago protein in wildtype MEFs was set to 1 . Data are mean \pm standard deviation for three trials. Inset shows representative data from a single experiment.

from the null hypothesis (noncooperative binding), although the Hill coefficients for the bulged and perfect siRNAs were significantly different $\left(n_{\text {bulged }}^{H}=1.8 \pm 0.5\right.$ versus $n_{\text {perfect }}^{H}=1.0 \pm$ $0.1 ; P=0.03$ ) (Supplemental Fig. S4B).

As a final test of the idea that noncooperative silencing reflects target cleavage, we analyzed silencing directed by a perfectly pairing siRNA in Ago $2^{-1-}$ MEFs reconstituted with D669A mutant Ago2. In the cells reconstituted with catalytically inactive Ago2, the single-site reporter was not silenced by the perfect siRNA (Supplemental Fig. S5). Surprisingly, cells reconstituted with catalytically inactive Ago2 exhibited noncooperative silencing of the six-site reporter by a perfect siRNA $\left(n_{\text {perfect }}^{H}=1.1 \pm 0.1\right)$, while silencing by a bulged siRNA displayed positive cooperativity $\left(n_{\text {bulged }}^{H}=1.5 \pm 0.3 ; P=0.04\right)$ (Fig. 5C). This unexpected result suggests that target cleavage per se is not required for noncooperative silencing mediated by Ago2. Rather, both the identity of the Argonaute protein and the nature of pairing between the small RNA and its target determine if RISC bound to multiple sites in the $3^{\prime}$ UTR of an mRNA can collaborate to generate cooperativity in silencing.

\section{Only Ago2-RISC can repress a reporter with nonadjacent sites}

In HeLa cells, the mRNA with the expanded target sites (Fig. 4A) was less efficiently silenced by a bulged siRNA than an mRNA in which the three sites were adjacent (Fig. 4B). We propose that RISCs bound to adjacent sites collaborate to achieve efficient silencing. Is Ago2 required to silence an
mRNA in which the small RNA binding sites cannot collaborate? We tested silencing of the expanded three-site reporter mRNA by the perfect and bulged siRNAs in the Ago $2^{-1-}$ MEFs. Silencing of the expanded three-site reporter was completely dependent on Ago2; little or no silencing was observed in the Ago $2^{-/-}$MEFs for either type of small RNA:target pairing (Fig. 7C,D). In contrast, both perfect and bulged siRNAs cooperatively silenced the reporter bearing three adjacent small RNA-binding sites in the Ago $2^{-1-}$ MEFs (Fig. 7A,B). Notably, in the absence of Ago2, silencing by the perfect siRNA of the reporter containing three adjacent sites was highly cooperative $\left(n_{\text {perfect }}^{H}=2.1 \pm 0.3 ; P=0.007\right)$. We conclude that, for widely spaced sites, only Ago 2 can silence at the intracellular RISC concentration achieved at the highest amount of siRNA transfected, likely because, in the absence of cooperativity, the intracellular concentration of Ago1-, Ago3-, and Ago4RISC is less than the $K_{D}$ for target binding for these Argonaute:siRNA complexes.

Reconstituting the Ago $2^{-/-}$MEFs with either wild-type or catalytically inactive mouse Ago 2 rescued silencing of the expanded three-site reporter (Fig. 7E-J). Silencing showed no significant cooperativity for the perfect siRNA in MEFs reconstituted with wild-type $\left(n_{\text {perfect }}^{H}=1.1 \pm 0.1\right)$ or catalytically inactive Ago2 $\left(n_{\text {perfect }}^{H}=1.2 \pm 0.2\right)$. Silencing by the bulged siRNA was cooperative for both the wild-type Ago2-reconstituted $\left(n_{\text {bulged }}^{H}=1.6 \pm 0.1 ; P=0.02\right)$ (Fig. 7F) and the catalytically inactive Ago2 MEFs $\left(n_{\text {bulged }}^{H}=1.3 \pm 0.2\right.$; $P=0.03$ ) (Fig. 7H). Intriguingly, in the absence of Agol, silencing of the expanded three-site reporter by the bulged siRNA was highly cooperative $\left(n_{\text {bulged }}^{H}=2.5 \pm 0.2 ; P=0.006\right)$ (Fig.7J).

\section{DISCUSSION}

In our assays, Ago2 noncooperatively silenced mRNAs bearing multiple, perfectly complementary small RNAbinding sites, even when its endoribonuclease activity was inactivated by mutation. This finding is surprising because we and others have assumed that endonucleolytic cleavage by Ago2 explained its lack of cooperativity in silencing when guided by a perfectly pairing siRNA. Clearly, a more complex explanation is warranted. We suggest that the Ago2 conformation associated with perfect small RNA:target pairing precludes protein:protein interactions, causing both nearby and adjacent binding sites to act independently. Alternatively, Ago2 protein, when guided by a small RNA that pairs extensively with its target mRNA, might be bound by proteins that prevent its association with factors promoting cooperativity.

Silencing via multiple small RNA-binding sites is likely always cooperative for Ago1, Ago3, or Ago4, irrespective of the type of pairing between the small RNA and its target. We suggest that these noncatalytic Argonaute proteins adopt a single conformation when bound by different 
A

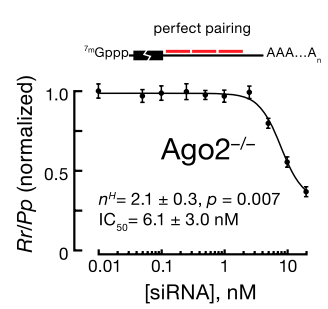

C

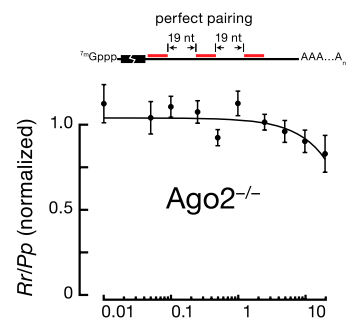

E

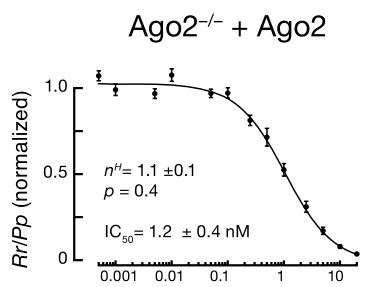

G

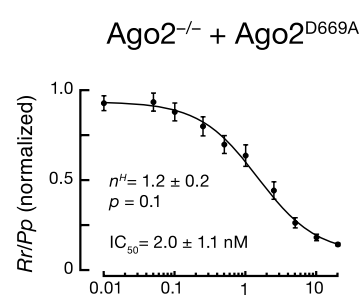

I

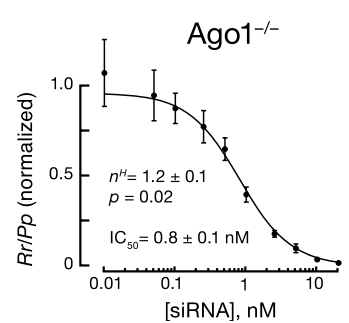

B

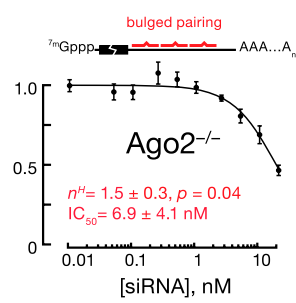

D

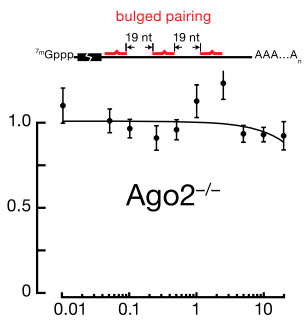

$\mathbf{F}$

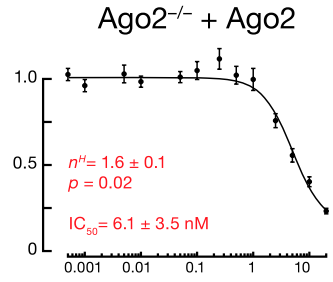

H
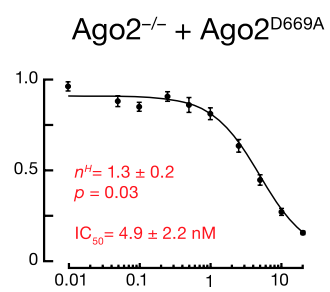

$\mathbf{J}$

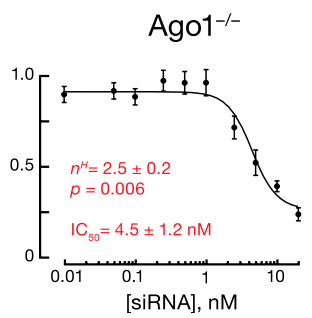

FIGURE 7. In the absence of Ago2, effective silencing requires adjacent sites. $(A, B)$ Both perfect $\left(n^{H}=2.1 \pm 0.3 ; P=0.007\right)$ and bulged $\left(n^{H}=1.5 \pm 0.3 ; P=0.04\right)$ adjacent sites were silenced cooperatively in the absence of Ago2. $(C, D)$ In Ago $2^{-1-}$ MEFs, three target sites spaced $19 \mathrm{nt}$ apart did not silence the reporter. $(E, F)$ Expressing mouse Ago2 in the Ago $2^{-l-}$ MEFs allowed three distant sites to silence the reporter. $(G, H)$ Expressing catalytically inactive, mutant Ago $2^{\mathrm{D} 669 \mathrm{~A}}$ also allowed three distant sites to silence the reporter. $(I, J)$ In the $\mathrm{Agol}^{-l-} \mathrm{MEFs}$ the three distant sites silenced the reporter. A one sample, two-tailed Student's $t$-test was used to calculate the $P$-values at $95 \%$ confidence for the Hill coefficients to determine if $n^{H}$ was significantly different from the null hypothesis: $n^{H}=1$ (i.e., noncooperative).

modes to their mRNA targets or that the conformations produced by both perfect and bulged small RNAs are compatible with protein:protein interactions between adjacent RISC molecules. Intrinsic differences between Ago2 and Ago1, Ago3, and Ago4 may dictate the combination of Ago proteins capable of cooperative silencing.

\section{Cooperativity versus statistical effects for closely apposed target sites}

We find that multiple, imperfect binding sites need to be surprisingly close in order to mediate cooperative silencing. Our data fundamentally agree with previous reports but differ quantitatively in the precise inter-site distance that supports cooperativity (Grimson et al. 2007; Bartel 2004. We note that the precise inter-site distance that supports cooperative interactions may reflect the intracellular concentrations of Argonaute proteins and associated factors, as well as the local structure or sequence of the mRNA target. When testing silencing of a two-site reporter, Grimson et al. observed that a seed-matched siRNA transfected at $25 \mathrm{nM}$ cooperatively silenced a reporter bearing two $3^{\prime}$ UTR target sites spaced 8-40 nt apart (counting the number of nucleotides between the $3^{\prime}$ end of the first site and the $5^{\prime}$ end of the second site); expanding the distance to $56 \mathrm{nt}$ disrupted cooperative silencing (Grimson et al. 2007). We note that these authors defined cooperativity as an excess of silencing when the observed repression for a two-site reporter was compared to the product of the repression observed for each site acting alone. Enhanced silencing measured in this way may correspond to true cooperativity or may simply reflect the statistical effects ${ }^{6}$ of multiple independent sites. Our Hill analyses distinguish between these two possibilities and suggest that RISCs bound to adjacent sites cooperate to confer greater silencing than would be expected from statistical effects alone.

\section{Supplemental $3^{\prime}$ pairing reduces the amount of small RNA required to repress an mRNA}

The amount of siRNA required to repress an mRNA target is determined by the number of small RNA-binding sites, the spacing of the sites, and the extent of complementarity beyond the seed sequence at each site. Compared to an mRNA in which the siRNA seed sequence alone paired with the small RNA-binding sites, an mRNA in which seed pairing was supplemented with additional $3^{\prime}$ base pairs

\footnotetext{
${ }^{6}$ Statistical effects result from the simultaneous occupancy of multiple, independent binding sites of similar affinities even in the absence of cooperativity (Cantor and Schimmel 1980). This effect, with increasing site occupancy, causes a steep threshold response that appears nonadditive. In contrast, cooperativity results in the concerted loading of sites at a lower overall concentration of ligand (e.g., miRISC) and a sharp dose-response to a relatively small increase in ligand concentration.
} 
required slightly less siRNA to achieve comparable repression, particularly for multisite target RNAs (Table 1; Fig. 2). These data reinforce the view that has emerged from previous computational analyses of miRNA target binding: $3^{\prime}$ supplemental pairing provides a small but measurable increase in the affinity of a small RNA for its target (Grimson et al. 2007).

Nonetheless, it is striking how much more siRNA is needed to regulate a target containing small RNA-binding sites with a seed-match only or a seed-match plus supplementary pairing, compared to a target containing sites that fully pair to the small RNA but for a central bulge. While our current data do not permit direct estimation of the binding affinity of a small RNA for a reporter mRNA within a cell, they suggest that one explanation for the remarkably high intracellular abundance of some miRNAs is that most miRNAs bind weakly to the mRNAs they regulate.

\section{MATERIALS AND METHODS}

\section{Plasmids}

Renilla luciferase vector pRL-TK (Promega) containing target sites for CXCR4 and a modified linker sequence (Doench et al. 2003) was mutated from TAG to CTC (lower case letters in the oligonucleotides) at nt 387-389 of the Renilla luciferase open reading frame to generate mismatches with seed positions 5,6 , and 7 of the siRNA guide strand by PCR-directed mutagenesis using DNA oligonucleotides:

\section{5' -CTTGTTTGGCATTTCATTACtccTATGAGCATCAAGATAAG ATC-3' (sense), \\ 5' -GATCTTATCTTGATGCTCATAGgagTAATGAAATGCCAAAC AAG-3' (antisense).}

Mutagenesis was confirmed by sequencing, and then $5^{\prime}$ phosphorylated oligos containing the target sites and pairing to create appropriate ends were cloned into the XbaI and ApaI sites of the mutant pRL-TK. Supplemental Table S3 lists the sequences of the DNA oligonucleotides used to construct target sites. psiCheck2 (Promega) reporters were constructed by digesting psiCheck2 with NheI and NotI and inserting the $3^{\prime}$ UTR target site-containing NheI-NotI fragment from the mutant pRL-TK vectors. Supplemental Table S3 lists the oligonucleotide sequences used to generate plasmid reporters. Dual Reporter Luciferase assays were conducted using Dual Luciferase Assay Reagents (Promega) in a Veritas Microplate Luminometer (Turner Biosystems) according to the manufacturer's directions.

\section{Cell culture and transfection}

HeLa CCL2 cell cultures were maintained at $37^{\circ} \mathrm{C}$ and $5 \% \mathrm{CO}_{2}$ in DMEM (Invitrogen) supplemented with $10 \%$ heat-inactivated FBS (Invitrogen) and $50 \mathrm{U} / \mathrm{mL}$ penicillin and streptomycin (Invitrogen). MEF cells were cultured in DMEM (Invitrogen) supplemented with 15\% heat-inactivated FBS (Invitrogen), $50 \mathrm{U} /$ $\mathrm{mL}$ penicillin and streptomycin (Invitrogen), $0.1 \mathrm{mM}$ NEAA (Invitrogen), $2 \mathrm{mM}$ glutamine (Invitrogen). Cells were seeded at a density of $0.1 \times 10^{6}$ cells per well in 24-well plates in DMEM
(Invitrogen) containing 10\% heat-inactivated FBS (Invitrogen). Twenty-four hours later, cells were washed three times in $500 \mu \mathrm{L}$ PBS (Invitrogen), and then $400 \mu \mathrm{L}$ DMEM with serum was added to each well. Renilla luciferase plasmid $(0.025 \mathrm{mg})$, firefly luciferase plasmid pGL3 $(0.025 \mathrm{mg})$, and $20 \mathrm{nM}$ siRNA were mixed with $99 \mu \mathrm{L}$ DMEM and $1 \mu \mathrm{L}$ DharmaFECT Duo (Dharmacon) per well. A control siRNA (CXCR4) was used to equalize the total amount of siRNA in each transfection. Cells are incubated with $0.5 \mathrm{~mL}$ final volume of DMEM plus serum containing $100 \mu \mathrm{L}$ of transfection reagent nucleic acid mixture for $24 \mathrm{~h}$.

\section{siRNA annealing}

Single-stranded guide and passenger siRNA strands (Dharmacon) (Supplemental Table S4) were annealed by incubating $10 \mu \mathrm{M}$ of each strand in $500 \mu \mathrm{L}$ annealing buffer $(100 \mathrm{mM}$ potassium acetate, $30 \mathrm{mM}$ HEPES-KOH, $\mathrm{pH}$ 7.4, $2 \mathrm{mM}$ magnesium acetate) for $1 \mathrm{~min}$ at $90^{\circ} \mathrm{C}$, followed by $1 \mathrm{~h}$ at $37^{\circ} \mathrm{C}$.

\section{Luciferase assays}

Cells were washed once in $500 \mu \mathrm{L}$ PBS and lysed in $100 \mathrm{~mL}$ of Passive Lysis Buffer (Promega) at room temperature for $20 \mathrm{~min}$ in 24 -well plates. For each well, $10 \mu \mathrm{L}$ lysate was read in triplicate using dual luciferase reagents (Promega) in a Turner Biosystems luminometer controlled by Veritas software (Turner). Renilla luciferase activity for each concentration of transfected siRNA was normalized to the corresponding firefly luciferase activity.

\section{Data analysis}

The individual biological replicates for normalized Renilla luciferase activity versus siRNA concentration were fit using Igor Pro 6.10 (Lake Oswego, OR) to the Hill equation to determine $\mathrm{IC}_{50}$ and $n^{H}$. Fitting was weighted using the standard error of each mean value. Throughout this study, the standard deviation is reported for mean $\mathrm{IC}_{50}$ and $n^{H}$ values. The Hill coefficients from each replicate were subjected to the Student's $t$-test to determine $P$-values at $95 \%$ confidence using GraphPad Prism (La Jolla, CA).

\section{Statistical testing}

To test if the individual Hill coefficients from the replicates of each experiment followed a Gaussian distribution, data were subjected to the Kolmogorov-Smirnov, D'Agostino-Pearson omnibus, and Shapiro-Wilk normality tests. By all three tests, all Hill coefficient data was normally distributed. The $P$-values at $95 \%$ confidence were calculated using an unpaired, one sample, two-tailed Student's $t$-test (GraphPad Prism) to test whether $n^{H}$ was significantly different from the null hypothesis that $n^{H}=1$ (i.e., noncooperative). An unpaired, two-tailed Student's $t$-test with Welch's correction at $95 \%$ confidence, which does not assume equal variances, was used to test the significance of differences in $n^{H}$ for a perfect and bulged siRNA. For non-normally distributed fold-repression data, we used the nonparametric Wilcoxon Signed-Rank test at $95 \%$ confidence to determine $P$-values.

\section{Western blotting}

Forty micrograms cell lysate in cell lysis buffer (50 mM Tris- $\mathrm{HCl}$, $150 \mathrm{mM} \mathrm{NaCl}, 1 \% \mathrm{v} / \mathrm{v}$ NP-40) containing Complete, mini, EDTA- 
free protease inhibitor (Roche) were separated by $4 \%-20 \%$ HEPES-SDS-PAGE and transferred at $4^{\circ} \mathrm{C}$ in Tris-bicine buffer to nitrocellulose membrane overnight at $30 \mathrm{~V}$. Membranes were blocked in 5\% w/v milk-TBST (100 mM Tris $\mathrm{Cl} \mathrm{pH} \mathrm{7.5,} 150 \mathrm{mM}$ $\mathrm{NaCl}, 0.1 \%$ TWEEN 20) for $1 \mathrm{~h}$ and incubated overnight at $4^{\circ} \mathrm{C}$ with primary antibody diluted in $3 \%$ milk-TBST. Rabbit antihuman and mouse Ago2 antibody (Cell Signaling Technologies) (Li et al. 2010) or rabbit anti-human and mouse Agol antibody (MBL International) were diluted 1:1000 and rabbit anti-actin antibody (Bethyl Laboratories) was diluted 1:5000. After three 5-min washes in TBST, the membranes were incubated $1 \mathrm{~h}$ with secondary goat anti-rabbit HRP-conjugated antibody (GE Healthcare) diluted 1:10,000. After five 5-min washes in TBST, the membranes were incubated for $5 \mathrm{~min}$ in Super Signal West-Dura Extended Duration Substrate (Pierce). Chemiluminescent signal was recorded using an LAS-4000 (Fuji).

\section{SUPPLEMENTAL MATERIAL}

Supplemental material is available for this article.

\section{ACKNOWLEDGMENTS}

We thank Dónal O'Carroll for his generous gift of MEF cell lines; Brian Farley and Hervé Seitz for help with curve fitting; the Aronin and Moore laboratories for reagents and equipment; Alicia Boucher, Karen Logan, Wayne Wilkin, Tiffanie Covello, and Gwen Farley for extraordinary technical support; and current and past members of the Zamore lab for advice and critical comments on the manuscript. This work was supported in part by grants from the National Institutes of Health (GM62862 and GM65236) to P.D.Z.

Received April 14, 2011; accepted July 14, 2011.

\section{REFERENCES}

Abrahante JE, Daul AL, Li M, Volk ML, Tennessen JM, Miller EA, Rougvie AE. 2003. The Caenorhabditis elegans hunchback-like gene lin-57/hbl-1 controls developmental time and is regulated by microRNAs. Dev Cell 4: 625-637.

Ameres SL, Martinez J, Schroeder R. 2007. Molecular basis for target RNA recognition and cleavage by human RISC. Cell 130: 101-112.

Azuma-Mukai A, Oguri H, Mituyama T, Qian ZR, Asai K, Siomi H, Siomi MC. 2008. Characterization of endogenous human Argonautes and their miRNA partners in RNA silencing. Proc Natl Acad Sci 105: 7964-7969.

Baek D, Villen J, Shin C, Camargo FD, Gygi SP, Bartel DP. 2008. The impact of microRNAs on protein output. Nature 455: 64-71.

Bartel DP. 2004. MicroRNAs: Genomics, biogenesis, mechanism, and function. Cell 116: 281-297.

Bartel DP, Chen CZ. 2004. Micromanagers of gene expression: The potentially widespread influence of metazoan microRNAs. Nat Rev Genet 5: 396-400.

Brennecke J, Stark A, Russell RB, Cohen SM. 2005. Principles of microRNA-target recognition. PLoS Biol 3: e85. doi: 10.1371/ journal.pbio.0030085.

Brown KM, Chu CY, Rana TM. 2005. Target accessibility dictates the potency of human RISC. Nat Struct Mol Biol 12: 469-470.

Cantor CR, Schimmel PR. 1980. Biophysical chemistry: Part III: The behavior of biological macromolecules (Their biophysical chemistry: Pt. 3). W. H. Freeman, New York.

Dahlgren C, Zhang HY, Du Q, Grahn M, Norstedt G, Wahlestedt C, Liang Z. 2008. Analysis of siRNA specificity on targets with double-nucleotide mismatches. Nucleic Acids Res 36: e53. doi: 10.1093/nar/gkn190.

Doench JG, Sharp PA. 2004. Specificity of microRNA target selection in translational repression. Genes Dev 18: 504-511.

Doench JG, Petersen CP, Sharp PA. 2003. siRNAs can function as miRNAs. Genes Dev 17: 438-442.

$\mathrm{Du} \mathrm{T}$, Zamore PD. 2007. Beginning to understand microRNA function. Cell Res 17: 661-663.

Du Q, Thonberg H, Wang J, Wahlestedt C, Liang Z. 2005. A systematic analysis of the silencing effects of an active siRNA at all single-nucleotide mismatched target sites. Nucleic Acids Res 33: 1671-1677.

Elbashir SM, Lendeckel W, Tuschl T. 2001a. RNA interference is mediated by 21- and 22-nucleotide RNAs. Genes Dev 15: 188-200.

Elbashir SM, Martinez J, Patkaniowska A, Lendeckel W, Tuschl T. 2001b. Functional anatomy of siRNAs for mediating efficient RNAi in Drosophila melanogaster embryo lysate. EMBO $J$ 20: $6877-6888$.

Eulalio A, Behm-Ansmant I, Schweizer D, Izaurralde E. 2007. P-body formation is a consequence, not the cause, of RNA-mediated gene silencing. Mol Cell Biol 27: 3970-3981.

Friedman RC, Farh KK, Burge CB, Bartel DP. 2009. Most mammalian mRNAs are conserved targets of microRNAs. Genome Res 19: 92105.

Ghildiyal M, Zamore PD. 2009. Small silencing RNAs: An expanding universe. Nat Rev Genet 10: 94-108.

Grimson A, Farh KK, Johnston WK, Garrett-Engele P, Lim LP, Bartel DP. 2007. MicroRNA targeting specificity in mammals: Determinants beyond seed pairing. Mol Cell 27: 91-105.

Guo H, Ingolia NT, Weissman JS, Bartel DP. 2010. Mammalian microRNAs predominantly act to decrease target mRNA levels. Nature 466: 835-840.

Haley B, Zamore PD. 2004. Kinetic analysis of the RNAi enzyme complex. Nat Struct Mol Biol 11: 599-606.

Hammond SM, Bernstein E, Beach D, Hannon GJ. 2000. An RNAdirected nuclease mediates post-transcriptional gene silencing in Drosophila cells. Nature 404: 293-296.

Hannon GJ. 2002. RNA interference. Nature 418: 244-251.

Haruki M, Tsunaka Y, Morikawa M, Iwai S, Kanaya S. 2000. Catalysis by Escherichia coli ribonuclease HI is facilitated by a phosphate group of the substrate. Biochemistry 39: 13939-13944.

Holen T, Amarzguioui M, Wiiger MT, Babaie E, Prydz H. 2002. Positional effects of short interfering RNAs targeting the human coagulation trigger Tissue Factor. Nucleic Acids Res 30: 1757-1766.

Huang H, Qiao R, Zhao D, Zhang T, Li Y, Yi F, Lai F, Hong J, Ding X, Yang Z, et al. 2009. Profiling of mismatch discrimination in RNAi enabled rational design of allele-specific siRNAs. Nucleic Acids Res 37: 7560-7569.

Hutvágner G, Zamore PD. 2002. A microRNA in a multiple-turnover RNAi enzyme complex. Science 297: 2056-2060.

Kanaya S, Oobatake M, Liu Y. 1996. Thermal stability of Escherichia coli ribonuclease $\mathrm{HI}$ and its active site mutants in the presence and absence of the $\mathrm{Mg}^{2+}$ ion. Proposal of a novel catalytic role for Glu48. J Biol Chem 271: 32729-32736.

Krek A, Grun D, Poy MN, Wolf R, Rosenberg L, Epstein EJ, MacMenamin P, da Piedade I, Gunsalus KC, Stoffel M, et al. 2005. Combinatorial microRNA target predictions. Nat Genet 37: 495-500.

Lai EC. 2002. Micro RNAs are complementary to 3' UTR sequence motifs that mediate negative post-transcriptional regulation. Nat Genet 30: 363-364.

Lee RC, Feinbaum RL, Ambros V. 1993. The C. elegans heterochronic gene lin-4 encodes small RNAs with antisense complementarity to lin-14. Cell 75: 843-854.

Lewis BP, Shih IH, Jones-Rhoades MW, Bartel DP, Burge CB. 2003. Prediction of mammalian microRNA targets. Cell 115: 787-798.

Lewis BP, Burge CB, Bartel DP. 2005. Conserved seed pairing, often flanked by adenosines, indicates that thousands of human genes are microRNA targets. Cell 120: 15-20. 
Li L, Yu C, Gao H, Li Y. 2010. Argonaute proteins: Potential biomarkers for human colon cancer. BMC Cancer 10: 38. doi: 10.1186/1471-2407-10-38.

Lim LP, Lau NC, Garrett-Engele P, Grimson A, Schelter JM, Castle J, Bartel DP, Linsley PS, Johnson JM. 2005. Microarray analysis shows that some microRNAs down-regulate large numbers of target mRNAs. Nature 433: 769-773.

Lin SY, Johnson SM, Abraham M, Vella MC, Pasquinelli A, Gamberi C, Gottlieb E, Slack FJ. 2003. The C. elegans hunchback homolog, $h b l-1$, controls temporal patterning and is a probable microRNA target. Dev Cell 4: 639-650.

Liu J, Carmell MA, Rivas FV, Marsden CG, Thomson JM, Song JJ, Hammond SM, Joshua-Tor L, Hannon GJ. 2004. Argonaute2 is the catalytic engine of mammalian RNAi. Science 305: 1437-1441.

Liu J, Rivas FV, Wohlschlegel J, Yates JR, Parker R, Hannon GJ. 2005. A role for the P-body component GW182 in microRNA function. Nat Cell Biol 7: 1161-1166.

Martinez J, Tuschl T. 2004. RISC is a $5^{\prime}$ phosphomonoester-producing RNA endonuclease. Genes Dev 18: 975-980.

Matranga C, Zamore PD. 2007. Primer. Small silencing RNAs. Curr Biol 17: R789-R793.

Meister G, Landthaler M, Patkaniowska A, Dorsett Y, Teng G, Tuschl T. 2004. Human Argonaute2 mediates RNA cleavage targeted by miRNAs and siRNAs. Mol Cell 15: 185-197.

O'Carroll D, Mecklenbrauker I, Das PP, Santana A, Koenig U, Enright AJ, Miska EA, Tarakhovsky A. 2007. A Slicer-independent role for Argonaute 2 in hematopoiesis and the microRNA pathway. Genes Dev 21: 1999-2004.

Olsen PH, Ambros V. 1999. The lin-4 regulatory RNA controls developmental timing in Caenorhabditis elegans by blocking LIN-14 protein synthesis after the initiation of translation. Dev Biol 216: 671-680.

Parker R, Sheth U. 2007. P bodies and the control of mRNA translation and degradation. Mol Cell 25: 635-646.

Rajewsky N, Socci ND. 2004. Computational identification of microRNA targets. Dev Biol 267: 529-535.

Rehwinkel J, Behm-Ansmant I, Gatfield D, Izaurralde E. 2005. A crucial role for GW182 and the DCP1:DCP2 decapping complex in miRNA-mediated gene silencing. RNA 11: 1640-1647.
Reinhart BJ, Slack FJ, Basson M, Pasquinelli AE, Bettinger JC, Rougvie AE, Horvitz HR, Ruvkun G. 2000. The 21-nucleotide let-7 RNA regulates developmental timing in Caenorhabditis elegans. Nature 403: 901-906.

Rivas FV, Tolia NH, Song JJ, Aragon JP, Liu J, Hannon GJ, JoshuaTor L. 2005. Purified Argonaute2 and an siRNA form recombinant human RISC. Nat Struct Mol Biol 12: 340-349.

Schwarz DS, Hutvágner G, Haley B, Zamore PD. 2002. Evidence that siRNAs function as guides, not primers, in the Drosophila and human RNAi pathways. Mol Cell 10: 537-548.

Schwarz DS, Hutvágner G, Du T, Xu Z, Aronin N, Zamore PD. 2003. Asymmetry in the assembly of the RNAi enzyme complex. Cell 115: 199-208.

Schwarz DS, Tomari Y, Zamore PD. 2004. The RNA-induced silencing complex is a $\mathrm{Mg}^{2+}$-dependent endonuclease. Curr Biol 14: 787-791.

Selbach M, Schwanhausser B, Thierfelder N, Fang Z, Khanin R, Rajewsky N. 2008. Widespread changes in protein synthesis induced by microRNAs. Nature 455: 58-63.

Song JJ, Smith SK, Hannon GJ, Joshua-Tor L. 2004. Crystal structure of Argonaute and its implications for RISC slicer activity. Science 305: 1434-1437.

Tafer H, Ameres SL, Obernosterer G, Gebeshuber CA, Schroeder R, Martinez J, Hofacker IL. 2008. The impact of target site accessibility on the design of effective siRNAs. Nat Biotechnol 26: 578-583.

Tolia NH, Joshua-Tor L. 2007. Slicer and the Argonautes. Nat Chem Biol 3: 36-43.

Vella MC, Choi EY, Lin SY, Reinert K, Slack FJ. 2004. The C. elegans microRNA let-7 binds to imperfect let-7 complementary sites from the lin-41 3' UTR. Genes Dev 18: 132-137.

Wightman B, Ha I, Ruvkun G. 1993. Post-transcriptional regulation of the heterochronic gene lin-14 by lin-4 mediates temporal pattern formation in C. elegans. Cell 75: 855-862.

Yekta S, Shih IH, Bartel DP. 2004. MicroRNA-directed cleavage of HOXB8 mRNA. Science 304: 594-596.

Zeng Y, Wagner EJ, Cullen BR. 2002. Both natural and designed micro RNAs can inhibit the expression of cognate mRNAs when expressed in human cells. Mol Cell 9: 1327-1333. 

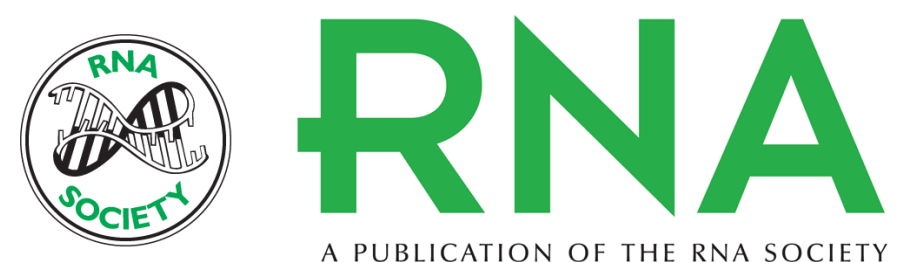

A PUBLICATION OF THE RNA SOCIETY

\section{Argonaute protein identity and pairing geometry determine cooperativity in mammalian RNA silencing}

Jennifer A. Broderick, William E. Salomon, Sean P. Ryder, et al.

RNA 2011 17: 1858-1869 originally published online August 30, 2011

Access the most recent version at doi:10.1261/rna.2778911

\section{Supplemental http://rnajournal.cshlp.org/content/suppl/2011/08/03/rna.2778911.DC1 \\ Material}

References This article cites 59 articles, 16 of which can be accessed free at: http://rnajournal.cshlp.org/content/17/10/1858.full.html\#ref-list-1

Open Access Freely available online through the RNA Open Access option.

License Freely available online through the RNA Open Access option.

Email Alerting Receive free email alerts when new articles cite this article - sign up in the box at the Service top right corner of the article or click here.

\section{|||||||| Providing Precise Solutions for your research.}

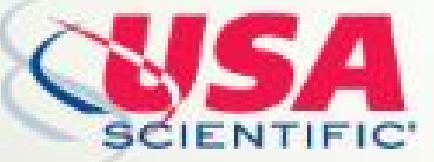

To subscribe to $R N A$ go to:

http://rnajournal.cshlp.org/subscriptions 